\title{
Patrick Chamoiseau, Édouard Glissant, Quando cadono i muri. L'identità nazionale fuorilegge?
}

\section{Alessandro Corio}

\section{(2) OpenEdition}

1 Journals

\section{Edizione digitale}

URL: http://journals.openedition.org/studifrancesi/8387

DOI: $10.4000 /$ studifrancesi.8387

ISSN: 2421-5856

\section{Editore}

Rosenberg \& Sellier

\section{Edizione cartacea}

Data di pubblicazione: 1 mai 2009

Paginazione: 215

ISSN: 0039-2944

\section{Notizia bibliografica digitale}

Alessandro Corio, «Patrick Chamoiseau, Édouard Glissant, Quando cadono i muri. L'identità nazionale fuorilegge?», Studi Francesi [Online], 157 (LIII | I) | 2009, online dal 30 novembre 2015, consultato il 12 janvier 2021. URL: http://journals.openedition.org/studifrancesi/8387 ; DOI: https://doi.org/10.4000/ studifrancesi.8387

Questo documento è stato generato automaticamente il 12 janvier 2021.

\section{(c) 9 (i) $\Theta$}

Studi Francesi è distribuita con Licenza Creative Commons Attribuzione - Non commerciale - Non opere derivate 4.0 Internazionale. 


\title{
Patrick Chamoiseau, Édouard Glissant, Quando cadono i muri. L'identità nazionale fuorilegge?
}

\author{
Alessandro Corio
}

\section{NOTIZIA}

PATRICK CHAMOISEAU, ÉDOUARD GLISSANT, Quando cadono i muri. L'identità nazionale fuorilegge?, trad. it. di Maria Pace Ottieri, Roma, i sassi - nottetempo, 2008, pp. 40.

«La tentazione del muro non è nuova. Ogni volta che una cultura o una civiltà non è riuscita a pensare l'altro, a pensarsi con l'altro, a pensare l'altro in sé, queste rigide difese di ferro, di filo spinato, di reti elettrificate o di ideologie chiuse si sono innalzate, sono crollate e ora ritornano con nuovi stridori» (p. 13). Il valore e l'efficacia di un pamphlet non si misurano certamente nella qualità dell'analisi teorica e del ragionamento filosofico, che si sono generalmente realizzati "a monte", bensì nella capacità di tradurli in un linguaggio semplificato, stimolante ed accessibile ad un pubblico più vasto, con delle finalità che potremmo definire, in senso lato, di pedagogia politica. Questo tentativo può dirsi pienamente riuscito nel caso di questo testo pubblicato nel 2007 da Patrick Chamoiseau e Édouard Glissant, col titolo Quand les murs tombent. L'identité nationale hors-la-lois?, ed ora tradotto in italiano da Maria Pace Ottieri - dove l'elemento che genera il disaccordo ed il conflitto consiste proprio nell'interpretazione che i due scrittori martinicani offrono del concetto di "identità nazionale". Il loro obbiettivo polemico istituzionale è la creazione in Francia, nel giugno del 2007, di un Ministero dell'Immigrazione, dell'Integrazione, dell'Identità Nazionale e dello Sviluppo solidale. La «supervalorizzazione identitaria», secondo gli autori, appare infatti storicamente connessa "a filo doppio" col progetto coloniale, con l'autogiustificazione della conquista e dello sfruttamento da parte delle potenze occidentali. Il modello di un'«identità a radice unica» è stato poi ripreso nel contesto delle lotte anti-coloniali e riprodotto così su scala planetaria. La presa di posizione dei 
due autori è netta: «Lo schema dello Stato-nazione si è [...] moltiplicato nel mondo. E ne sono derivati solo disastri» (p. 8). Per uscire dalla deriva autoritaria, populista e xenofoba che il modello nazionalista ripropone costantemente, dobbiamo anche guardare oltre quella semplice giustapposizione di etnie e di culture, proposta dal modello multiculturalista, e muoverci invece consapevolmente verso modelli di identità relazionale. I muri che si innalzano oggi, infatti, nelle loro molteplici forme non separano realmente popoli, identità o culture, ma la povertà dalla sovrabbondanza, nascondendo quest'evidenza dietro il deplorevole ritornello dello scontro di civiltà.

Al cuore della questione, di schiacciante attualità in tutta l'Europa, Italia compresa, sta la percezione e la gestione dei flussi migratori, utilizzata sempre più come spauracchio da parte delle élites dominanti: «Ma come si può credere che oggi la nazione francese sia messa in pericolo in modo così profondo, e che il flusso dei due o trecentomila immigrati illegali che provengono dai paesi poveri dell'Africa costituisca il nocciolo duro di questa minaccia?» (p. 9). Ma la vera, fondamentale questione che emerge è la seguente: può davvero l'Europa di oggi permettersi di rifiutare la grande ricchezza, materiale e culturale, che proviene dalla relazione dinamica con le diversità? Il progetto dell'Occidente è già da sempre attraversato dall'alterità, e la vera sfida della "mondialità" oggi consiste nella liberazione degli immaginari, nell'accettare che il diverso penetri ed infranga le rigidità identitarie. Non si tratta di dissolvere le singolarità, ma di lasciare che queste entrino in rapporto con il mondo e si arricchiscano reciprocamente: «Non è perché una comunità accoglie degli stranieri, accoglie le loro differenze, perfino le loro opacità, che si snatura o rischia di morire. Al contrario, si accresce e si completa» (p.28). Ed in effetti, uno dei messaggi che giungono al lettore in modo più chiaro e diretto da questo testo è proprio l'accostamento della dimensione e della vocazione relazionale dell'identità, aperta nei confronti del cambiamento, dello scambio, della trasformazione, con un elemento che, fuori da questo contesto, potrebbe apparirci quasi naïf: la bellezza, la poesia. È su questa dimensione palpabile del sentire umano che, in fin dei conti, i due scrittori fanno leva nel momento in cui formulano un appello per sollevare una protesta contro un'istituzione che, dietro a parole d'ordine quali "integrazione", "tolleranza delle differenze", "cosviluppo", cerca di «abituarci poco a poco all'insopportabile, di portarci a frequentare, in silenzio e fino al rischio della complicità, l'inammissibile. Tutto il contrario della bellezza» (p. 35). 